\title{
Estimação da Estrutura a Termo da Curva de Juros no Brasil através de Modelos Paramétricos e Não Paramétricos
}

\section{Estimation of the Term Structure of Yield Curve in Brazil using Parametric and Non-Parametric Models}

\begin{abstract}
Resumo: O presente trabalho compara os principais métodos de interpolação e ajuste da estrutura a termo da curva de juros e apresenta os principais conceitos relativos às curvas de juros, que são de grande importância tanto para formuladores de políticas quanto para participantes do mercado em geral, principalmente aqueles que atuam diretamente na gestão de carteiras de títulos de renda fixa. Os resultados encontrados mostram a superioridade dos modelos baseados em splines, modelos não paramétricos, em relação aos modelos paramétricos no que diz respeito ao ajuste da curva de juros. Por outro lado, a interpretação econômica dos fatores que compõe os modelos paramétricos e seu bom desempenho para fazer previsões da curva de juros faz com que recebam muita atenção, tanto de pesquisadores quanto de participantes do mercado em geral nos últimos anos.
\end{abstract}

Palavras-chave: Curva de juros. Taxas à vista. Taxas forward. Modelos paramétricos. Modelos não paramétricos.

\begin{abstract}
The present paper compares the principal methods for interpolation and adjustment of the yield curve and presents the main concepts relative to the curve, which are of great importance for both policy makers and market participants in general, especially those who directly participate in managing portfolios of fixed income securities. The results show the superiority of nonparametric models in relation to parametric models with respect to the adjustment of the yield curve. On the other hand, the economic interpretation of the factors that make up the parametric models and their good performance to predict the yield curve has drawn much attention from both researchers and market participants in recent years.
\end{abstract}

\footnotetext{
* $\quad$ Doutor em Economia pelo Programa de Pós-Graduação em Economia (PPGE). Professor
} do Departamento de Economia da UFRGS. E-mail: joao.caldeira@ufrgs.br 
Keywords: Yield curve. Sport rate. Forward rate. Parametric models. Nonparametric models.

JEL Classification: C32; C52; G11.

\section{Introdução}

Estrutura a termo ${ }^{1}$ é uma função que relaciona determinada variável financeira ou parâmetros, a suas maturidades. Exemplos comuns são a estrutura a termo da taxa de juros ou preços dos zero-cupom bonds. Mas existem também estrutura a termo de volatilidade implícita de opções, spreads de crédito, swaps de variância ${ }^{2}$ etc. Estrutura a termo são objetos de alta dimensionalidade, os quais frequentemente não são diretamente observáveis. Do ponto de vista empírico, isso requer métodos de estimação que sejam flexíveis o suficiente para capturar a totalidade das informações do mercado, mas, muitas vezes, flexibilidade se tem ao custo de formas irregulares da estrutura a termo e grande número de fatores. Análise de componentes principais e métodos de estimação paramétricos podem colocar as coisas no lugar.

$\mathrm{O}$ uso da estrutura a termo da taxa de juros em finanças e macroeconomia tem sido uma ativa linha de pesquisa nos últimos 30 anos. Para macroeconomistas, a estrutura a termo fornece informações a respeito da expectativa de inflação futura e de crescimento do produto. Por exemplo, Stock e Watson (1989) examinam diversas variáveis econômicas com finalidade de construir um indicador líder e mostram que o spread entre o commercial paper e as notas do tesouro, ambos de seis meses, apresentam o melhor desempenho na previsão do ciclo de negócios. Harvey (1989; 1991), mostra que embora os índices do mercado acionário sejam relevantes para prever o crescimento do produto, a estrutura a termo da taxa de juros pode explicar mais de 50\% da variação do crescimento do PIB dos países que compõem o G-7, no período de 1969 a 1989. Estrella e Hardouvelis (1991) fazem testes do poder preditivo do spread entre títulos de dez anos e três meses para o PIB e seus componentes, mostram que o spread é significativo para previsão do PIB, consumo e investimento. Mais trabalhos relacionando a estrutura a termo com variáveis macroeconômicas são Haubrich e Drombosky (1996), Estrella e Minshkin (1996), Minshkin (1990) e Estrella e Minshkin (1997), entre outros.

$1 \quad$ O termo de um instrumento de dívida com uma maturidade fixada é o tempo até a maturidade.

2 Seja um índice de mercado $S$, um swap de variância troca o pagamento da variância realizada do log dos retornos de $S$ por um preço (strike) previamente acordado. 
O uso da estrutura a termo da taxa de juros em finanças e macroeconomia tem sido uma ativa linha de pesquisa nos últimos 30 anos. Para macroeconomistas, a estrutura a termo fornece informações a respeito da expectativa de inflação futura e de crescimento do produto. Por exemplo, Stock e Watson (1989) examinam diversas variáveis econômicas com finalidade de construir um indicador líder e mostram que o spread entre o commercial paper e as notas do tesouro, ambos de seis meses, apresentam o melhor desempenho na previsão do ciclo de negócios. Harvey (1989; 1991), mostra que, embora os índices do mercado acionário sejam relevantes para prever o crescimento do produto, a estrutura a termo da taxa de juros pode explicar mais de $50 \%$ da variação do crescimento do PIB dos países que compõem o G-7, no período de 1969 a 1989. Estrella e Hardouvelis (1991) fazem testes do poder preditivo do spread entre títulos de dez anos e três meses para o PIB e seus componentes, mostram que o spread é significativo para previsão do PIB, consumo e investimento. Mais trabalhos relacionando a estrutura a termo com variáveis macroeconômicas são Haubrich e Drombosky (1996), Estrella e Minshkin (1996), Minshkin (1990) e Estrella e Minshkin (1997), entre outros.

Para finanças, o uso da estrutura a termo é importante para tomada de decisões de investimento, precificação de derivativos e para hedgear operações e carteiras de títulos de renda fixa. Do lado da modelagem encontramos várias questões desafiadoras. Títulos e outros contratos forward expiram em maturidades em que tem de satisfazer uma condição terminal formalmente predeterminada. Por exemplo, títulos zero-cupom têm valor $\$ 1,00$ na maturidade, uma opção europeia tem um payoff predeterminado contingente a algum instrumento base etc. Sob condição de não arbitragem, isso tem implicações não triviais para qualquer modelo dinâmico da estrutura a termo. Como consequência, várias abordagens para modelar a estrutura a termo da taxa de juros foram propostas nas últimas décadas, modelagens que visam ao ajuste da curva de juros, como em McCulloch (1971; 1975), Heath, Jarrow e Morton (1992) e Svensson (1994a), entre outros. Desde a década de 70, a literatura passou a construir modelos de fatores não observáveis (modelos afins) para representar e prever a curva de juros, a começar pelo trabalho seminal de Vasicek (1977) e Cox, Ingersoll Jr e Ross (1985), em que os autores usam um único fator para modelar a curva de juros. Já Litterman e Scheinkman (1991) e Dai e Singleton (2002), utilizando análise de componentes principais, chegam a conclusão de que de dois a três fatores - nível, inclinação e curvatura - são suficientes para modelar a curva de juros. E modelagens que buscam prever a estrutura a termo, tendo como referência original o trabalho de Nelson e Siegel (1987), 
posteriormente, Duffie e Kan (1996), Diebold e Li (2006), Diebold, Rudebusch e Aruoba (2006), Bowsher e Meeks (2008) e Koopman, Mallee e Van der Wel (2010), entre outros.

Apesar dos resultados satisfatórios, os modelos de fatores não fornecem uma interpretação econômica, especialmente como a curva de juros responde a choques advindos de variáveis macroeconômicas. A abordagem macrofinanceira que visa a identificar os principais fatores macroeconômicos responsáveis pelas variações da curva de juros, Ang e Piazzesi (2003). Basicamente, os autores incluem variáveis macro no vetor de variáveis não observáveis e concluem que as variáveis macroeconômicas explicam uma proporção significativa dos movimentos na curva de juros. Outros autores como Diebold, Rudebusch e Aruoba (2006) e Hordahl et al. (2006), ampliam a abordagem de Ang e Piazzesi (2003) utilizando modelos macroeconômicos juntamente com o modelo afim da curva de juros.

No Brasil vários autores têm dedicado atenção ao estudo da curva de juros, (TABAK; TABATA, 2004; BRITO, 2001; ALMEIDA et al., 2009; CAJUEIRO; DIVINO; TABAK, 2009; LAURINI; HOTTA, 2010; CALDEIRA; MOURA; PORTUGAL, 2010), entre outros. Para uma abrangente revisão da literatura sobre curva de juros, ver Rossi (1996).

Do ponto de vista prático, entretanto, os dados disponíveis não fornecem uma completa curva da estrutura a termo, o que se observa é um conjunto discreto de pontos relacionando taxas de juros às diferentes maturidades. Para superar este problema, é necessário algum método de interpolação para construir uma curva contínua. No mercado de títulos (com ou sem cupom) existe um amplo espectro quanto à data dos seus vencimentos (maturidades), indo desde os títulos que estão por vencer até o caso daqueles que na verdade nunca vencem, como ocorre, por exemplo, com uma perpetuidade que paga eternamente a taxa de juros correspondente ao valor do cupom.

As formas de modelar a estrutura a termo das taxas de juros pode ser dividida em métodos paramétricos e não paramétricos, baseados em splines. Os métodos paramétricos apresentam algumas vantagens. Primeiro, assumem especificações parcimoniosas, que propiciam interpretação econômica dos parâmetros. Segundo, podem ser impostas formas funcionais que obedecem relações impostas pela teoria econômica. E, terceiro, como apontam Laurini e Moura (2010), métodos paramétricos podem ser testados contra modelos aninhados para testar se as relações impostas pela teoria são válidas. Alguns exemplos típicos de modelos de interpolação paramétrica podem ser encontrados em Nelson e Siegel (1987) e Svensson (1994b). Entretanto, como discutido por Hagan e West (2006), os métodos paramétricos não são imunes a problemas. 
Primeiro, eles falham quanto ao requerimento de positividade nas curvas interpoladas para taxas à vista e taxas forward, condição necessária para eliminar oportunidades de arbitragem. Segundo, a estabilidade local das curvas ajustadas pode ser comprometida, um simples ruído na curva pode resultar em deterioração do ajuste. Finalmente, a construção da função de desconto, derivada das taxas de juros à vista, pode resultar em uma função não decrescente como requerido.

Do outro lado, estão os modelos que buscam extrair a estrutura a termo em qualquer ponto do tempo utilizando dados dos preços dos títulos empregando técnicas de estimação por cross-section. McCulloch (1971; 1975) foi o pioneiro neste campo, seus trabalhos sobre estimação da estrutura a termo baseada em splines marcaram um passo significativo, servindo como base para muitos dos atuais trabalhos acadêmicos a este respeito. Conforme discutido em Laurini e Moura (2010), os métodos não paramétricos apresentam muitas vantagens em relação aos métodos paramétricos. Primeiro, desde que eles não assumem uma particular forma funcional, eles são robustos em relação a erros de má especificação. Segundo, métodos não paramétricos podem ser usados como um primeiro passo na análise dos dados para guiar o esforço de especificação. Terceiro, a estimação não paramétrica pode ser bastante factível quando o tamanho da amostra é pequena e são impostas restrições apropriadas quanto à forma. Para interpolação não paramétrica, usualmente os métodos empregados são funções de aproximação quadrática piecewise introduzida por McCulloch (1971; 1975), sendo as mais populares interpolações por cubic splines, discutidas em mais detalhe na seção 3.1.2. Outros modelos são exponencial splines (Vasicek, 1977) e mais recentemente formulações bayesianas de exponencial splines, Yu e Zivot (2008).

Vale destacar que os modelos não paramétricos, ou modelos de não arbitragem, têm foco no perfeito ajuste da estrutura a termo em um dado ponto do tempo, assegurando que não existam possibilidades de arbitragem, o que é importante para o apreçamento de derivativos. Já os modelos de equilíbrio, classe de modelos paramétricos, têm foco na modelagem da taxa instantânea, utilizando tipicamente modelos afins, depois disso, as taxas para outros vencimentos podem ser derivadas sob várias suposições acerca do prêmio de risco (ver, por exemplo, Vasicek (1977), Cox, Ingersoll Jr. e Ross (1985), Hull e White (1990) e Heath, Jarrow e Morton (1992), entre outros).

Existem dois problemas fundamentais que precisam ser mencionados em qualquer modelo que tente estimar a estrutura a termo da taxa de juros (EETJ, daqui em diante) implícita no preço dos títulos. $\mathrm{O}$ primeiro problema são as lacunas, no que diz respeito aos vencimentos 
dos títulos. Nem sempre estão disponíveis no mercado títulos vencendo em todos os prazos que se deseja. Segundo, a ETTJ é definida em termos de títulos com desconto puro ou zero-cupom e, na grande maioria dos mercados, o que se encontra são títulos que fazem pagamento de cupom. Estes dois fatos levam a problemas práticos de estimação. Primeiro, há a decisão de como preencher as lacunas - qual é o formato que a estrutura a termo deve ter? Para responder a essa questão, deve-se decidir pelo trade-off entre alisamento dos dados (remoção dos ruídos) e representatividade (flexibilidade de manter os vértices genuínos na estrutura a termo).

O objetivo do presente trabalho é o de comparar modelos de estimação exata da estrutura a termo da taxa de juros, amplamente usados em operações de hedge e precificação de títulos e derivativos no mercado brasileiro. Os métodos analisados são interpolações lineares, interpolação de Raw (exponencial) e o cubic spline de McCulloch (1971; 1975) que é amplamente difundido no mercado financeiro brasileiro. Além disso, são apresentados conceitos básicos relativos à curva de juros, como curva spot, curva forward, curva forward instantânea e suas inter-relações. Também são discutidas as técnicas usadas na imunização de carteiras de títulos e na construção de estratégias. Além desta introdução, o artigo está organizado da seguinte forma. Na Seção 2, são apresentados alguns conceitos e algumas definições acerca de curva de juros, bem como relações entre as diferentes taxas. Na seção 3, são discutidos modelos empregados na interpolação e ajuste da curva de juros. A seção 4, apresenta os dados usados na análise, além disso, são comparados empiricamente os modelos paramétricos e não paramétricos para ajuste da curva de juros. A seção 5 conclui o artigo.

\section{Taxas de Juros à Vista (Spot Rates) e Taxas Forward (Forward Rates)}

Um título é uma forma de empréstimo securitizado (FILIPOVIC, 2009). Títulos são instrumentos que podem ser usados por governos ou empresas privadas para financiar suas atividades; são instrumentos de dívida, os quais, diferentemente de ações, não implicam propriedade da firma por parte do comprador. Basicamente, o comprador de um título empresta dinheiro ao emissor, por um intervalo de tempo que termina na maturidade do título. Na maturidade, o emissor paga ao detentor do título uma quantidade de dinheiro correspondente ao valor de face, também chamado o valor do par, do título. Além disso, podem ser feitos pagamentos periódicos, chamados cupons por razões históricas. Esta 
seção fornece alguns conceitos básicos de taxas de juros e títulos negociados no mercado. A começar por títulos zero-cupom, e definimos um número de taxas de juros relacionadas a eles.

\subsection{Título Zero-Cupom}

Existe uma classe de títulos, a qual apenas promete o pagamento do valor de face na maturidade. São chamados de títulos zero-cupom (zero-cupon bonds) e são tipicamente caracterizados por curtas maturidades. Os títulos zero-cupom são fundamentais para precificação de títulos, conforme será visto. Um real hoje vale mais que um real amanhã. $\mathrm{O}$ valor de um real em $t$, com $\tau \leq \mathrm{t}$ pode ser expresso por um título zero-cupom ('zero-cupom bond') com maturidade $\tau, P_{t}(\tau)$. Isto é um contrato o qual garante ao seu detentor um real a ser pago na maturidade $\tau$. Tais instrumentos são títulos de renda fixa que fazem um único pagamento em uma data futura, conhecida como maturidade. Em teoria, assumimos que:

- Existe um mercado sem fricção para títulos zero-cupom para todo $\tau>0$.

- $P \tau(\tau)=1$ para todo $\tau$

- $\mathrm{P}_{\mathrm{t}}(\tau)$ é diferenciável em $\tau$.

Na prática, estas suposições nem sempre são satisfeitas. Não existem títulos (zero-cupom) negociados para todas as maturidades, e $P_{t}(\tau)$ pode ser menor que $\$ 1,00$ no caso de default do emissor. A terceira condição é puramente técnica e implica que a estrutura a termo dos preços dos títulos zero-cupom, $\tau \rightarrow P_{t}(\tau)$ é uma curva suave.

Para estabelecer a relação entre as taxas de juros de curto e longo prazos no contexto de títulos zero-cupom, considere-se inicialmente o caso sem incerteza, sem custo de transação e com perfeita visão do futuro. O investidor compara o retorno de duas estratégias de aplicação financeira. Na primeira, compra um título do governo com maturidade $\tau_{N}$, mantendo-o até o vencimento. Na segunda, compra uma Letra do Tesouro de um período, reinvestindo o resultado (principal mais os juros) na compra e uma nova Letra do Tesouro para o período seguinte, repetindo a operação nos próximos períodos até $N$. Cumpre ressaltar que a Letra do Tesouro é um tipo de ativo com desconto puro, pois não há qualquer pagamento de cupom. Vale dizer, o título é vendido com um desconto, sendo amortizado pelo seu valor de face. Desta forma, a percentagem do ganho de capital sobre o preço de compra é a taxa de juros que o ativo paga. 


\subsubsection{Taxa de Juros: Definição}

A taxa interna de retorno, ou simplesmente yield to maturity, no tempo $t$ de um título com maturidade em $\tau$ é definida implicitamente como a taxa $y_{t}(\tau)$ que desconta seu fluxo de pagamentos obtendo o preço $P$ :

$$
P_{t}(\tau)=\sum_{i=1}^{n} C_{i} e^{-\left(t_{i}-t\right) y_{t}(\tau)}
$$

O lado direito da expressão é o valor presente, descontado à taxa $y_{t}(\tau)$, dos pagamentos de restantes para o detentor do título. Para um título zero- cupom, a expressão reduz-se a:

$$
P_{t}(\tau)=e^{-\tau y_{t}(\tau)}
$$

O preço $P_{t}(\tau)$ de um título zero-cupom é esperado crescer gradualmente com o tempo $t$ até a maturidade $\tau$, quando alcança seu máximo (SHILLER; MCCULLOCH, 1987), igual a \$1,00. O aumento no preço do título ao longo do período em que ele é mantido representa o retorno para o seu detentor. O verdadeiro aumento no preço, uma vez que é determinado pelas forças do mercado, pode não ser estável, e oscilar ao longo do tempo. Assim, é útil ter alguma medida do aumento futuro no preço do título que está implícito em $P_{t}(\tau)$. O yield to maturity (taxa interna de retorno) $y_{t}(\tau)$ no tempo $t$, para um título com maturidade $\tau$, pode ser definido, dado $P_{t}(\tau)$ como a taxa estável, à qual o preço do título deveria crescer, para que o título valha $\$ 1,00$ no vencimento. A estrutura a termo da taxa de juros no tempo $t$ é a função relacionando yield to maturity a maturidades $\tau=\left(\tau_{1}, \tau_{2}, \ldots, \tau_{N}\right)$. Um gráfico de $y_{t}(\tau)$ contra $\tau$ é conhecido como curva de juros em $t$.

Geralmente os títulos não são negociados pelos seus preços nem pelas suas yield to maturity, e sim por suas taxas anualizadas. Além disso, as taxas anualizadas de um título dependem da convenção acerca da forma como os juros são compostos. A estimação de curvas de juros zero-cupom é baseada em uma relação funcional entre as taxas à vista, taxas forward ou fatores de desconto de um lado e maturidades do outro. Fatores de desconto são quantidades usadas em determinada data $\mathrm{t}$ para obter o valor presente de fluxos de caixa futuros. Uma função de desconto é uma coleção de fatores de desconto na data $t$ para todas as maturidades $\tau$. As taxas de juros $y_{t}(\tau)$, o yield ganho em títulos zerocupom, são relacionados aos fatores de desconto por (lembramos que o valor de face do título é sempre $\$ 1,00)$ : 


$$
P_{t}(\tau)=e^{-y_{t}(\tau) \tau} \quad \text { e } \quad y_{t}(\tau)=-\frac{\log \left(P_{t}(\tau)\right)}{\tau}
$$

onde $y_{t}(\tau)$ é o valor da taxa anualizada de um zero-cupom com vencimento em $\tau$ e negociado a $P_{t}(\tau)$ em $t(\mathrm{t} \leq \tau)$, e $\tau$ é maturidade do título.

Em nossa análise, consideramos que os títulos zero-cupom estão isentos da possibilidade de default. Assim, as taxas às quais os títulos estão sendo negociados são indicativas de dois fatores: i. o valor intertemporal do dinheiro e ii. o risco associado à volatilidade da taxa de juros de curto prazo.

Se um investidor compra um título zero-cupom em t e o mantém até o vencimento em $\tau(t \leq \tau)$, ele receberá $\$ 1,00$. Não há risco nessa operação, entretanto ele estará com seu capital indisponível entre os períodos $t$ e $\tau$, portanto, demanda uma remuneração, por isso, chamamos esse fator de valor intertemporal do dinheiro.

Além disso, se o investidor considera a possibilidade de se desfazer do título antes de seu vencimento, ele está exposto ao risco de que variações na taxa de juros de curto prazo alterem o valor de revenda do título. Um título que paga $\$ 1,00 \mathrm{em} \tau$, pode valer menos, em $(\mathrm{t} \leq \tau)$, caso ocorram aumentos na taxa de juros de curto prazo. Esse é o risco associado à volatilidade da taxa de juros. É importante salientar que, em nenhuma dessas situações, o investidor está exposto ao risco associado à saúde financeira do emissor.

\subsection{Taxa Forward e Taxa Forward Instantânea}

As taxas forwards implícitas são facilmente calculadas a partir das taxas à vista, desde que um investimento forward com datas de liquidação em maturidade específicas possam ser reproduzido por uma venda e uma compra de título zero-cupom: vende um título com maturidade igual à data de liquidação do contrato forward e compra um título com mesmo valor de mercado e que vence na data de maturidade do contrato forward. A taxa forward implícita é o retorno obtido de uma carteira de títulos com esse formato (SVENSSON, 1994b).

Mais precisamente, seja $f_{\mathrm{t}}\left(\tau_{1}, \tau_{2}\right)$ a taxa forward (implícita) continuamente composta do contrato forward negociado no tempo $t$, para um investimento que começa em $\tau_{1}>t$, a data da liquidação e encerramento em $\tau_{2}>\tau_{1}$, a maturidade. Então, a taxa forward relaciona-se com a taxa à vista da seguinte forma:

$$
f_{t}\left(\tau_{1}, \tau_{2}\right)=\frac{\tau_{2} y_{t}\left(\tau_{2}\right)-\tau_{1} y_{t}\left(\tau_{1}\right)}{\tau_{2}-\tau_{1}}
$$


Isto é, a taxa forward para um investimento de um ano, com liquidação em quatro anos $\left(\tau_{1}-t=4\right.$ anos) e maturidade em 5 anos $\left(\tau_{1}-t=\right.$ 5 anos) ('a taxa forward para um ano quatro anos à frente') é igual a 5 vezes a taxa à vista para 5 anos menos 4 vezes a taxa à vista para 4 anos.

A taxa forward instantânea é a taxa forward para um contrato futuro com um período de investimento infinitesimal após a data de liquidação, e é definida como o limite:

$$
f_{t}\left(\tau_{1}\right)=\lim _{\tau_{2} \rightarrow \tau_{1}} f_{t}\left(\tau_{2}, \tau_{1}\right)
$$

Na prática, pode ser identificada com uma taxa forward overnight, isto é, a taxa forward com maturidade um dia após a liquidação. A taxa forward com maturidade finita $f_{t}\left(\tau_{1}, \tau_{2}\right)$, com $\tau_{1}<\tau_{2}$, é obtida a partir da média das taxas forwards instantâneas com liquidação entre $\tau_{1}$ e $\tau_{2}$,

$$
f_{t}\left(\tau_{1}, \tau_{2}\right)=\frac{\int_{\tau_{1}}^{\tau_{2}} f_{t}(\tau) d \tau}{\tau_{2}-\tau_{1}}
$$

A taxa forward instantânea pode ser vista como o acréscimo marginal no retorno total de um aumento marginal no tamanho do investimento. Taxas forwards instantâneas e taxas à vista com maturidades infinitas são, portanto, relacionadas como custo médio e custo marginal da produção, se o tempo até a maturidade é identificado como a quantidade produzida. A taxa à vista $y_{t}(\tau)$ no tempo $t$ com maturidade $\tau$ é, consequentemente, idêntica à média das taxas forwards instantâneas com liquidação entre a data da negociação, $t$ e a data da maturidade, $\tau$.

$$
y_{t}(\tau) \equiv \frac{\int_{t}^{\tau} f_{t}(\tau) d \tau}{\tau_{2}-t}
$$

Equivalentemente, as taxas forwards e taxas à vista satisfazem a seguinte relação:

$$
f_{t}(\tau) \equiv y_{t}(\tau)+(\tau-t) \frac{\partial y_{t}(\tau)}{\partial t}
$$

a qual é outra relação padrão entre custo médio e custo marginal, com o tempo até a maturidade $\tau$ correspondendo à quantidade produzida. Consequentemente, quando olhamos para curvas de juros forwards e à vista, frequentemente identificamos as formas das curvas de custo marginal e custos médios familiares dos livros de microeconomia. 
Em vista da incerteza com relação à taxa de juros futura, o investidor pode preferir contratar esse valor previamente (forward rate). A taxa de juros contratada é obtida das taxas (spot) de juros para períodos de tempo no futuro. Suponha, por exemplo, que as taxas spot para investimentos de um e dois anos sejam, respectivamente, 10\% e 11\%. Assim, a taxa forward contratada para vigorar entre o primeiro e o segundo anos, deve ter valor tal que, uma vez considerada a taxa spot para o investimento de um ano (10\%), renderia o mesmo que uma aplicação de dois anos contratada à taxa spot de $11 \%$. Mais precisamente, usando-se capitalização contínua e considerando-se um capital de $\$ 1,00$, tem-se:

$$
e^{0.10} e^{f}=e^{0.11(2)}
$$

ou seja, $f=0,12$, que é, a taxa forward para o ano dois. Vê-se, assim, que a relação entre as taxas forwards e as taxas spot é dada por:

$$
f_{t}=\frac{\left[y_{t}\left(\tau_{2}\right) \tau_{2}-y_{t}\left(\tau_{1}\right) \tau_{1}\right]}{\left(\tau_{2}-\tau_{1}\right)}
$$

Onde $f_{t}\left(\tau_{1}, \tau_{2}\right) y_{t}(\tau 2)$ e $y_{t}\left(\tau_{1}\right)$ são, respectivamente, a taxa forward, e as taxas spot para investimentos em $\tau_{2}$ e $\tau_{1}$ onde $\tau_{2}>\tau_{1}$, conforme apresentado acima.

\section{Interpolações e Ajuste da Estrutura a Termo da Curva de Juros}

Em qualquer ponto do tempo thaverá uma série de títulos de dívida diferindo pela maturidade, $\tau$, e pelo fluxo de pagamentos. Naturalmente, nem todas as maturidades possíveis serão observadas nos títulos disponíveis em qualquer tempo $t$, e para algumas maturidades existirá mais que um título disponível. No entanto, para os participantes do mercado e formuladores de políticas, é importante associar à qualquer maturidade a taxa de juros que vigoraria caso um título fosse negociado naquele vencimento, ou seja, é importante obter uma curva de juros completa ou, ao menos, uma boa aproximação desta. A forma mais comum de tratar o problema é obter taxas interpoladas a partir das taxas de juros dos títulos com maturidades que são efetivamente negociadas.

No mercado de títulos (com ou sem cupom), há um amplo espectro quanto às maturidades, indo desde os títulos que estão por vencer até o caso daqueles que na verdade nunca vencem, como ocorre, por exemplo, com uma perpetuidade que paga eternamente a taxa de juros correspondente ao valor do cupom. A estrutura a termo da taxa 
de juros é a relação, na data $t$, entre as taxas de juros $y_{t}(\tau)$ para distintas maturidades dos títulos, $\tau=\left(\tau_{1}, \tau_{2}, \ldots, \tau_{N}\right)$. Vale dizer, a estrutura a termo faz a ligação entre as taxas de juros de curto e de longo prazos. Como as taxas de juros de curto prazo respondem à política monetária e essas taxas afetam as taxas de longo prazo, que são importantes nas decisões de investimento do setor privado, é importante que se conheça como essas taxas se inter-relacionam nas várias situações. ${ }^{3}$

No entanto, a ausência geral de títulos disponíveis com desconto puro que possam ser usados para computar a curva de juros zero cupom apresenta um problema para os agentes. Em outras palavras, taxas de títulos zero-cupom são raramente observáveis diretamente nos mercados financeiros. A tentativa de extrair taxas de juros zero-cupom dos preços de instrumentos livres de risco que fazem pagamento de cupons, os quais são observáveis, por exemplo, títulos públicos, levou ao desenvolvimento de vários modelos e inúmeras técnicas numéricas. Tais modelos podem ser amplamente categorizados em paramétricos e abordagens baseadas em splines (não paramétricos), em que um diferente trade-off entre a flexibilidade para representar as formas geralmente associadas com a curva de juros (qualidade do ajuste) e suavidade caracteriza as diferentes abordagens.

A forma mais usual de se aproximar taxas não observadas é por interpolação. As técnicas de interpolação são as mais variadas. Normalmente, utilizam-se polinômios com formas conhecidas (como os de Legendre ou Bernstein) como funções que ligam as maturidades às taxas de juros. Não há um modelo teórico por trás dessa abordagem. Supõe-se que a estrutura a termo possa ser explicada por uma função $f$ (normalmente, essa função é um polinômio). Estimam-se, então, os coeficientes da função (polinômio) que melhor se ajustam às taxas de fato observadas no mercado. Na prática, o grau do polinômio é escolhido de forma que as taxas calculadas a partir do polinômio para as maturidades observadas tenham ajuste perfeito às taxas, de fato, observadas. De posse desses coeficientes, é possível, dado que conhecemos a forma funcional da função (polinômio), obtém-se a taxa de juros associada a qualquer maturidade. A estrutura a termo obtida com esse método é chamada de curva de juros interpolada.

Em termos de ajuste às taxas observadas, as técnicas de interpolação são bastante flexíveis, desde que se use uma função de interpolação de grau suficientemente alto, é possível garantir o ajuste da estrutura interpolada à estrutura observada. Entretanto, como a interpolação de uma estrutura a termo não está associada a condições de equilíbrio ou

Para mais detalhes a esse respeito, ver Filipovic (2009). 
não arbitragem, os resultados, assim obtidos, admitem oportunidades de arbitragem, uma propriedade não desejável em qualquer modelo possa ser utilizado para precificar diferentes ativos ou explicar a dinâmica temporal da curva de juros. As principais abordagens para modelar a curva de juros (conforme relatório do Bank for International Settlements - BIS, 2005) são discutidas brevemente a seguir.

\subsection{Modelos Não Paramétricos de Interpolação da Curva de Juros}

Nas construções teóricas, é comum assumir uma estrutura a termo para um continuum de maturidades $\tau$. Em outras palavras, assume-se que a curva forward ou curva de juros zero-cupom é dada por uma função da variável contínua $\tau$. Porém, isso deve ser visto como uma aproximação da realidade, a qual apresenta um número finito de cotações observadas no mercado. Entretanto, à medida que mais derivativos com fluxos de caixa que diferem das maturidades observadas no mercado precisam ser precificados, é necessário interpolar a estrutura a termo. Nesta seção apresentamos alguns dos métodos mais usados para interpolar e ajustar a estrutura a termo da curva de juros.

Interpolação é uma técnica usada para estimar valores de funções em pontos intermediários de intervalos, a partir de valores da função calculados nos extremos desses intervalos. A seguir, discutimos alguns dos métodos mais usados pelos bancos centrais ao redor do mundo e por participantes do mercado, para ajustar e interpolar a estrutura a termo da curva de juros, conforme relatório do Departamento Monetário e Econômico do BIS (2005) (na Tabela 1 do relatório, são apresentados os modelos utilizados pelos principais bancos centrais para construção da curva de juros).

\subsubsection{Interpolação Exponencial}

Este método é linear no logaritmo dos fatores de desconto. Além de ser muito estável, é simples para implementar e geralmente é o método básico implementado antes de qualquer outro. Desde que a taxa forward instantânea é $f(\tau)=\frac{\partial y(\tau)}{\partial \tau} \tau$, a função de interpolação para a curva de juros é $y(\tau)=K+\frac{C}{\tau} \partial \tau$. Dados os dois pontos extremos, resolve-se
como:

$$
\begin{gathered}
f(\tau)=K=\frac{y_{i+1} \tau_{i+1}-y_{i} \tau_{i}}{\tau_{i+1}-\tau_{i}} \\
C=\frac{\left(y_{i}-y_{i+1}\right) \tau_{i} \tau_{i+1}}{\tau_{i+1}-\tau_{i}}
\end{gathered}
$$


E com algum exercício de álgebra obtemos:

$$
y(\tau)=\left(\frac{\tau-\tau_{i}}{\tau_{i+1}-\tau_{i}}\right) \frac{\tau_{i+1}}{\tau} y_{i+1}+\left(\frac{\tau_{i+1}-\tau}{\tau_{i+1}-\tau_{i}}\right) \frac{\tau_{i}}{\tau} y_{i+1}
$$

Este método às vezes é chamado de interpolação exponencial, dado que envolve interpolação exponencial do fator de desconto:

$$
P(\tau)=P_{i+1}^{\left(\frac{\tau-\tau_{i}}{\tau_{i+1}-\tau_{i}}\right)} \times P_{i}^{\left(\frac{\tau_{i+1}-\tau}{\tau_{i+1}-\tau_{i}}\right)}
$$

Isto é equivalente à interpolação linear do logaritmo dos fatores de desconto, o que não deveria ser surpresa, uma vez que:

$$
f(\tau)=-\frac{\partial \ln P(\tau)}{\partial \tau}
$$

E assim o modelo de forward constante é facilmente visto como equivalente a este tipo de interpolação linear.

\subsubsection{Métodos baseados em Splines - Cubic Spline}

Ao invés de especificar uma forma funcional para todo o conjunto de maturidades, os métodos baseados em splines ajustam a curva de juros com base em um polinômio por partes (piecewise), a função spline, ${ }^{4}$ onde cada segmento individual é conectado suavemente nos chamados nós (knot points, ou vértices da curva de juros). Para um intervalo fechado, uma dada função contínua pode ser aproximada selecionando um polinômio arbitrário, onde a qualidade do ajuste aumenta com a ordem do polinômio. Entretanto, polinômios de alta ordem, frequentemente, apresentam insuficientes propriedades de suavização. Consequentemente, funções splines são geralmente baseadas em polinômios de baixa ordem (principalmente quadrático ou cúbico). Um cubic spline, por exemplo, é um polinômio cúbico por pontos (piecewise) restrito nos vértices ( $k n o t$ points) tal que seu nível e as duas primeiras derivadas são idênticos. Um parâmetro corresponde a cada knot no spline.

A ideia fundamental por trás da interpolação por cubic spline é baseada na ferramenta da engenharia usada para desenhar curvas suaves

4 Funções Spline ou B-splines são usados no contexto de estimação de curva de juros. É comum, entre os participantes do mercado, haver confusão entre funções splines e interpolação baseada em splines. A primeira técnica consiste em usar polinômios para aproximar funções (desconhecidas), a segunda é simplesmente um método específico para interpolar entre dois pontos dos dados. 
através de um conjunto de pontos. Os splines consistem de pesos atribuídos, de forma a gerar uma superfície nos pontos a serem conectados. Uma linha flexível é estendida entre cada um desses pontos, resultando em curva agradavelmente suave.

Como antes, seja $\tau_{1}, \tau_{2}, \ldots, \tau_{N}$ e $y_{1}, y_{2}, \ldots, y_{N}$ conhecidos. Para completar um cubic spline, são necessários os coeficientes $\left(a_{i}, b_{i}, c_{i}, d_{i}\right)$ para $1 \leq i \leq$ $n-1$. Dados estes coeficientes, a função valor para qualquer maturidade $\tau$ será:

$$
y(\tau)=a_{i}+b_{i}\left(\tau-\tau_{i}\right)+c_{i}\left(\tau-\tau_{i}\right)^{2}+d_{i}\left(\tau-\tau_{i}\right)^{3}
$$

Com

$$
\begin{aligned}
y^{\prime}(\tau) & =b_{i}+2 c_{i}\left(\tau-\tau_{i}\right)+3 d_{i}\left(\tau-\tau_{i}\right)^{2} \\
y^{\prime \prime}(\tau) & =2 c_{i}+6 d_{i}\left(\tau-\tau_{i}\right) \\
y^{\prime \prime \prime}(\tau) & =6 d_{i} \\
\tau_{i} \leq \tau \leq \tau_{i}+1 . &
\end{aligned}
$$

Façamos $h_{i}=\tau_{i+1}-\tau_{i}$ daqui em diante. As restrições impostas são:

- a função de interpolação passa pelos dados (pontos), assim $a_{i}=$ $y_{i}$ para $i=1,2, \ldots, n-1$ e $a_{n-1}+b_{n-1} h_{n-1}+c_{n-1} h_{n-1}^{2}+d_{n-1} h^{3}{ }_{n-1}=y_{n}=a_{n}$;

- a função de interpolação passa pelos dados (pontos), assim $a_{i}+b_{i} h_{i}+c_{i} h_{i}^{2}+d_{i} h_{i}^{3}=a_{i+1}$ para $i=1,2, \ldots, n-2$;

- a função de interpolação é totalmente diferenciável, assim $b_{i}+2 c_{i} h_{i}+3 d_{i} h_{i}=b_{i+1}$ para $i=1,2, \ldots, n-2$.

O que constitui um sistema com 3n-4 equações com $4 n$-4 parâmetros desconhecidos. Assim, existem ainda $n$ restrições lineares a serem especificadas.

Uma condição fundamental para requerer-se diferenciabilidade da função de interpolação é que a função forward $f(\tau)=\frac{\partial y(\tau)}{\partial \tau} \tau$ seja
contínua. Assim, tem-se:

$$
f(\tau)=a_{i}+b\left(2 \tau_{i}-\tau\right)+c_{i}\left(\tau_{i}-\tau\right)\left(3 \tau-\tau_{i}\right)+d_{i}\left(\tau-\tau_{i}\right)^{2}\left(4 \tau-\tau_{i}\right) .
$$

Para $\tau_{i} \leq \tau \leq \tau_{i+1}$. 
Definindo

$$
b_{n}=b_{n-1}+2 c_{n-1} h_{n-1}+3 d_{n-1} h_{n-1}^{2}
$$

Assim, $b_{n}$ é a derivada da função de interpolação à direita do ponto extremo superior. No caso mais geral, a especificação das demais $n$ restrições é equivalente à especificação de $\left(b_{1}, b_{2}, \ldots, b_{n}\right)$. Em particular, se definirmos $\left(b_{1}, b_{2}, \ldots, b_{n}\right)$, então, $\left(c_{1}, c_{2}, \ldots, c_{n}\right)$ e $\left(d_{1}, d_{2}, \ldots, d_{n}\right)$ seguem facilmente, para cada $i$, temos duas equações com dois parâmetros desconhecidos, às quais se resolve como:

$$
\begin{aligned}
m_{i} & =\frac{a_{i+1}-a_{i}}{h_{i}} \\
c_{i} & =\frac{3 m_{i}-b_{i+1}-2 b_{i}}{h_{i}} \\
d_{i} & =\frac{b_{i+1}+b_{i}-2 m_{i}}{h_{i}}
\end{aligned}
$$

Para $i=1,2, \ldots, n-1$.

\subsubsection{Cubic Spline Natural}

O método cubic spline, com a chamada condição de fronteira natural é a única função de interpolação cubic spline onde as $n$ condições extras são:

- a função de interpolação é duas vezes diferenciável: $c_{i}+3 d_{i} h_{i}=$ $c_{i}+1$ para $i=1,2, \ldots, n-1$;

- a segunda derivada em, cada extremo é zero.

Esse método pode satisfatoriamente ser implementado para curvas com um conjunto denso de vértices, mas é qualitativamente não satisfatório para curvas com um conjunto de vértices mais esparsos. A curva é muito convexa entre os pontos que estão mais distantes uns dos outros. Em particular, este método não garante que curvas forward negativas não aconteçam. Outra desvantagem bem conhecida do cubic spline é que as estimativas das taxas forwards podem ser bastante instáveis, especialmente nas maturidades mais longas (SHEA, 1984). 


\subsection{Modelo Fama e Bliss}

O procedimento de Fama e Bliss (1987) considera a estrutura a termo das taxas de juros em termos de taxa de juros a termo. O modelo de Fama-Bliss não suavizado faz a extração de taxas de juros a termo dos preços dos títulos através de uma função de desconto. A função de desconto é estendida a cada passo através da taxa de juros a termo necessário para apreçar sucessivamente títulos com vencimentos mais longos resultando na função de retorno ajustada ao item previamente incluído. A taxa de juros a termo resultante deste procedimento é uma função com saltos (descontínua) em relação ao vencimento do título que está sendo utilizado. Este procedimento é amplamente utilizado no Brasil, é conhecido no mercado financeiro como flat forward e de acordo com Bliss (1997), é conhecido em Wall Street como bootstrap.

\subsection{Modelos Paramétricos da curva de juros}

O princípio básico dos modelos paramétricos está na especificação de uma função valor, que é definida sobre todo o domínio das maturidades. Enquanto as várias abordagens nesta classe de modelos defendem diferentes escolhas da função, compartilham a abordagem geral de que os parâmetros do modelo sejam determinados através da minimização dos desvios quadrados dos preços observados em relação aos teóricos.

\subsubsection{Modelo de Nelson-Siegel}

Diebold e Li (2006) reinterpretaram o modelo proposto por Nelson e Siegel (1987), que consideram uma forma paramétrica para o comportamento da estrutura a termo ao longo do tempo, na qual os coeficientes são tratados como nível, inclinação e curvatura da curva de juros.

$$
y_{t}(\tau)=\beta_{1, t}+\beta_{2, t}\left(\frac{1-e^{\lambda_{t} \tau}}{\lambda_{t} \tau}\right)+\beta_{3, t}\left(\frac{1-e^{\lambda_{t} \tau}}{\lambda_{t} \tau}-e^{\lambda_{t} \tau}\right)
$$

Para as maturidades longas, as taxas à vista e forwards aproximam assintoticamente do valor $\beta_{0}$, o qual deve ser positivo. $\left(\beta_{0}+\beta_{1}\right)$ determinam o valor inicial da curva na maturidade zero; assim, $\beta_{1}$ representa o desvio da assíntota $\beta_{0}$. Além disso, $\left(\beta_{0}+\beta_{1}\right)$ também deve ser positivo. Os dois parâmetros restantes $\beta_{2}$ e $\tau$ são responsáveis pela curvatura. A magnitude da curvatura é dada pelo valor absoluto de $\beta_{2}$, enquanto a direção é dada pelo sinal: um sinal negativo indica uma forma de $U$, enquanto um sinal positivo indica forma de $U$ invertido; $\tau$, o qual também deve ser positivo, determina a posição da curvatura. 


\subsubsection{Modelo de Suensson}

Para melhorar a flexibilidade das curvas e o ajuste, Svensson (1994b) amplia o modelo de Nelson e Siegel (1987), adicionando um outro termo que possibilita uma segunda curvatura. A precisão extra é alcançada ao custo de adicionar mais dois parâmetros, $\beta_{4}$ e $\tau_{2}$, os quais precisam ser estimados. A curva de juros resultante é dada por:

$$
y_{t}(\tau)=\beta_{1, t}+\beta_{2, t}\left(\frac{1-e^{\lambda_{1 t} \tau}}{\lambda_{1 t} \tau}\right)+\beta_{3, t}\left(\frac{1-e^{\lambda_{1 t} \tau}}{\lambda_{1 t} \tau}-e^{\lambda_{11} \tau}\right)+\beta_{4, t}\left(\frac{1-e^{\lambda_{2 t} \tau}}{\lambda_{2 t} \tau}-e^{\lambda_{2 t} \tau}\right)
$$

O método de Svensson (1994b) é mais flexível e geralmente tem melhor ajuste que o modelo de Nelson e Siegel (1987), com o custo de ser menos parcimonioso.

\section{Dados e Comparação das Técnicas de Interpolação}

Nesta seção ilustramos o uso das principais metodologias de interpolação e ajuste da curva de juros. Comparamos os modelos paramétricos de Nelson-Siegel e Svensson-Nelson-Siegel, do lado dos modelos não paramétricos, são empregados os modelos cubic splines, proposto por McCulloch (1971; 1975) e modelo de interpolação exponencial. Essas metodologias foram escolhidas por se tratarem das mais empregadas tanto por bancos centrais ao redor do mundo quanto por participantes do mercado financeiro em geral. Os dados empregados consistem dos preços diários de fechamento dos contratos de DI futuro negociados na BMËF. O período analisado vai de 23/02/2007 a 22/04/2010, 5 perfazendo um total de 793 observações diárias. A Figura 1 mostra o comportamento diário da curva de juros para o período analisado. É importante destacar que esta curva de juros foi obtida via interpolação por cubic splices (McCul-loch, 1971; 1975) considerando-se maturidades fixas. Nota-se os vários formatos assumidos pela estrutura a termo da curva de juros, com períodos em que apresenta inclinações positivas, inclinações negativas e períodos com mais de uma inversão. Assim a amostra parece adequada para comparar a performance das diferentes metodologias de ajuste.

$\overline{5} \quad$ Foram utilizados dados referentes a todos os contratos negociados no período, mesmo aqueles que apresentaram baixa liquidez. 


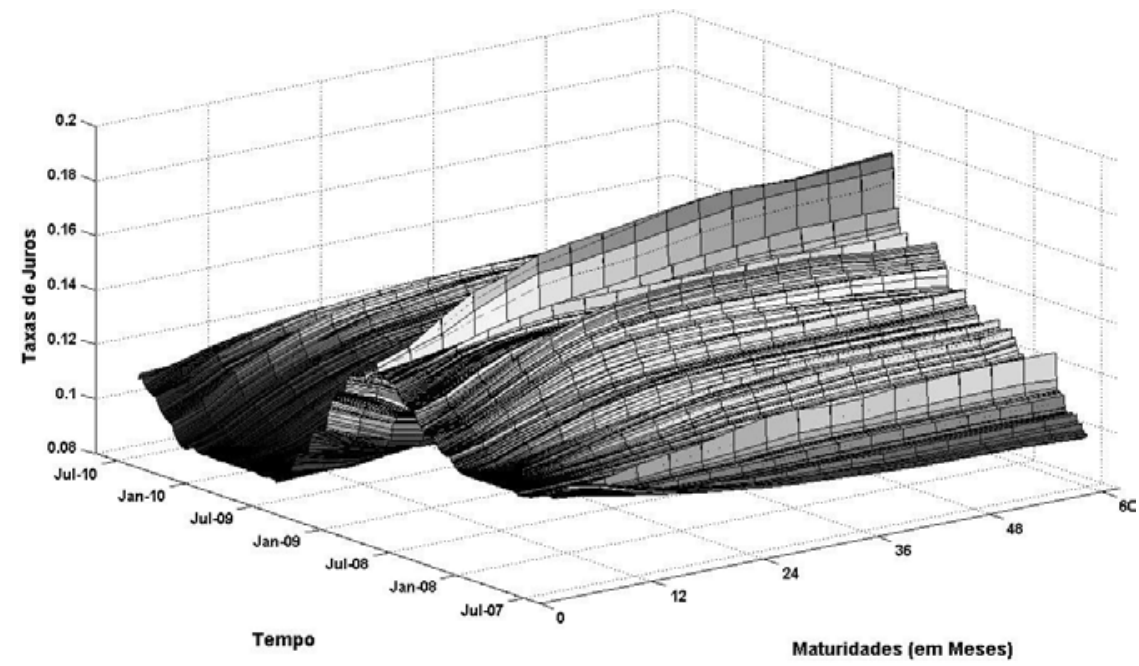

Figura 1 - Estrutura a termo da curva de juros (jul. 2007 a jul. 2010) Fonte: Elaborada pelo autor.

Nota: Curva de juros obtida via interpolação por cubic splines.

A Tabela 1 resume algumas estatísticas descritivas da curva de juros para o período. Nota-se que as taxas para maturidades mais curtas apresentam maior volatilidade, o que é um fato estilizado na literatura sobre curva de juros. Outro ponto a destacar é que, mesmo se tratando de um período amostral não muito longo, percebe-se ampla variação entre as taxas mínimas e máximas para todas as maturidades, refletindo o comportamento da política monetária no período. As três últimas colunas trazem as autorrelações com defasagens de 1, 5 e 21 dias úteis. Observa-se também que as taxas de juros para maturidades mais curtas exibem maior persistência para os três níveis de defasagens analisados, o que está de acordo com a literatura relacionada ao tema.

Tabela 1 - Estatísticas Descritivas da Curva de Juros (Fev-07 a Jul-10)

\begin{tabular}{lllllllll}
\hline Maturidades & Média & Mediana & Std Dev & Mínimo & Máximo & ACF(1) & ACF(5) & ACF(21) \\
\hline M1 & 0.1085 & 0.1112 & 0.0165 & 0.0851 & 0.1413 & 0.9993 & 0.9949 & 0.9617 \\
M3 & 0.1092 & 0.1116 & 0.0168 & 0.0859 & 0.1452 & 0.9994 & 0.9961 & 0.9646 \\
M6 & 0.1111 & 0.117 & 0.172 & 0.0861 & 0.1532 & 0.9993 & 0.9954 & 0.9609 \\
M9 & 0.1133 & 0.1120 & 0.0174 & 0.0873 & 0.1604 & 0.9987 & 0.9929 & 0.9490 \\
M12 & 0.1157 & 0.1131 & 0.0173 & 0.0899 & 0.1640 & 0.9980 & 0.9901 & 0.9354 \\
M15 & 0.1180 & 0.1143 & 0.0170 & 0.0935 & 0.1692 & 0.9972 & 0.9866 & 0.9202 \\
M18 & 0.1199 & 0.1153 & 0.0165 & 0.0955 & 0.1712 & 0.9964 & 0.9828 & 0.9023 \\
M21 & 0.1214 & 0.1168 & 0.0159 & 0.0979 & 0.1726 & 0.9956 & 0.9791 & 0.8829 \\
\hline
\end{tabular}

(continua...) 
(continuação)

\begin{tabular}{lllllllll}
\hline M24 & 0.1226 & 0.1182 & 0.0154 & 0.1006 & 0.1744 & 0.9947 & 0.9752 & 0.8641 \\
M27 & 0.1235 & 0.1197 & 0.0150 & 0.1027 & 0.1762 & 0.9941 & 0.9717 & 0.8454 \\
M30 & 0.1242 & 0.1203 & 0.0147 & 0.1023 & 0.1778 & 0.9934 & 0.9681 & 0.8273 \\
M33 & 0.1248 & 0.1209 & 0.0144 & 0.1018 & 0.1789 & 0.9926 & 0.9645 & 0.8105 \\
M36 & 0.1252 & 0.1215 & 0.0140 & 0.1017 & 0.1783 & 0.9920 & 0.9616 & 0.7972 \\
M39 & 0.1257 & 0.1221 & 0.0136 & 0.1016 & 0.1781 & 0.9911 & 0.9585 & 0.7834 \\
M42 & 0.1260 & 0.1225 & 0.0133 & 0.1014 & 0.1793 & 0.9904 & 0.9552 & 0.7718 \\
M48 & 0.1266 & 0.1231 & 0.0131 & 0.1009 & 0.1800 & 0.9896 & 0.9514 & 0.7527 \\
M60 & 0.1274 & 0.1244 & 0.0128 & 0.1003 & 0.1810 & 0.9882 & 0.9444 & 0.7294 \\
\hline
\end{tabular}

Fonte: Elaborada pelo autor.

Nota: Apresentamos estatísticas descritivas das taxas de juros diárias para diferentes maturidades. As três últimas colunas contêm autocorrelações com defasagens de 1, 5 e 21 dias úteis, respectivamente.

Nas Figuras 2 a 5, são apresentadas a curva de juros real (observada) e a curva ajusta pelos três diferentes métodos analisados, abordagem baseada em splines (cubic-spline), modelo de Svenson e modelo de Nelson-Siegel. A qualidade do ajuste de cada metodologia é analisada em diferentes situações da estrutura a termo da curva de juros, considerando períodos de inclinação positiva, curva invertida e inclinação negativa. Isso permite verificar se alguma metodologia apresenta melhor desempenho para determinados formatos da curva de juros.

A Figura 2 traz a curva de juros para o dia 06/08/2007, período em que a curva de juros brasileira apresentava inversão de inclinação, com inclinação negativa para as maturidades de até 10 meses e inclinação positiva daí em diante, refletindo a expectativa do mercado de que o Banco Central elevaria a taxa básica de juros a partir do início de 2008 como forma de conter processo de elevação da inflação, ${ }^{6} \mathrm{O}$ que veio a se confirmar em abril de 2008, quando iniciou-se o ciclo de aumentos dos juros. Fica evidente que os métodos não paramétricos, baseados em splines (cubic spline), ajustam-se perfeitamente à curva de juros observada. Já nos métodos paramétricos, nota-se que o modelo de Svensson apresenta melhor desempenho para as maturidades mais curtas, principalmente devido à inclusão do fator adicional de curvatura, condizente com o formato da curva analisado, já o modelo de NelsonSiegel apresenta ajuste levemente inferior para as maturidades curtas e intermediárias.

6 Desde 1999, quando o Brasil passou a adotar o regime de metas para inflação, a política monetária (principalmente a taxa SELIC) passou a ser direcionada, principalmente, para manter a inflação dentro da meta. 
Na Figura 3 temos a curva de juros do dia 03/06/2008, tanto a curva real quanto a ajustada pelos quatro métodos analisados. Nesse período, as taxas para as maturidades mais curtas embutiam expectativas de elevação, já a partir das maturidades intermediárias a curva de juros apresentava inclinação descendente, apresentando uma curvatura bem definida por volta da maturidade de 20 meses. Neste caso, onde a curva de juros apresenta uma curvatura bem definida, a superioridade dos modelos não paramétricos não fica tão evidente. Já os modelos paramétricos apresentam ajuste bastante similar, com o de Svensson superando o modelo de Nelson-Siegel para as maturidades mais curtas.

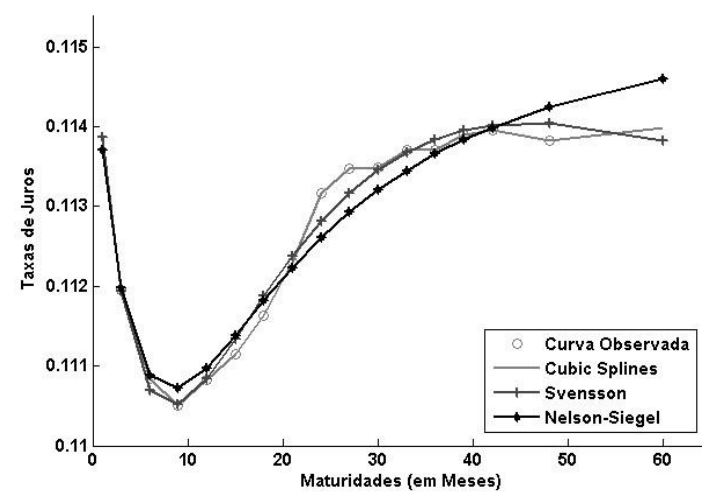

Figura 2 - Curva de juros observada e ajustada - 06/08/2007 Fonte: Elaborada pelo autor.

Nota: Círculos $=$ curva de juros observada, Cinza $=$ curva interpolada por cubic splines, $+=$ ajustada pelo modelo de Svensson $e^{*}=$ ajustada pelo modelo de Nelson-Siegel.

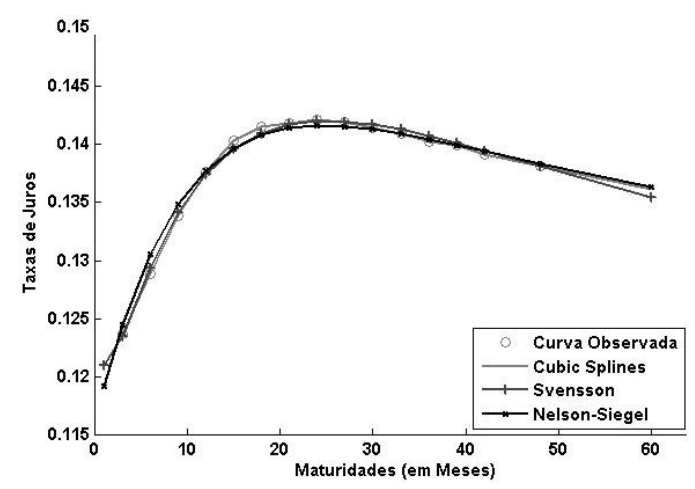

Figura 3 - Curva de juros observada e ajustada - 03/06/2008 Fonte: Elaborada pelo autor.

Nota: Círculos $=$ curva de juros observada, Cinza $=$ curva interpolada por cubic splines, $+=$ ajustada pelo modelo de Svensson e * $=$ ajustada pelo modelo de Nelson-Siegel. 
A curva de juros do dia 30/01/2009, apresentada na Figura 4, não difere muito do formato apresentado na Figura 2, porém, neste último caso, as taxas de juros para as maturidades mais curtas estão em um patamar mais elevado e a curva não apresenta inversão acentuada de inclinação. Neste caso a superioridade dos modelos não paramétricos não é tão destacada, exceto que os modelos de Svensson e NelsonSiegel apresentam ajuste relativamente pobre para as maturidades entre 30 e 40 meses.

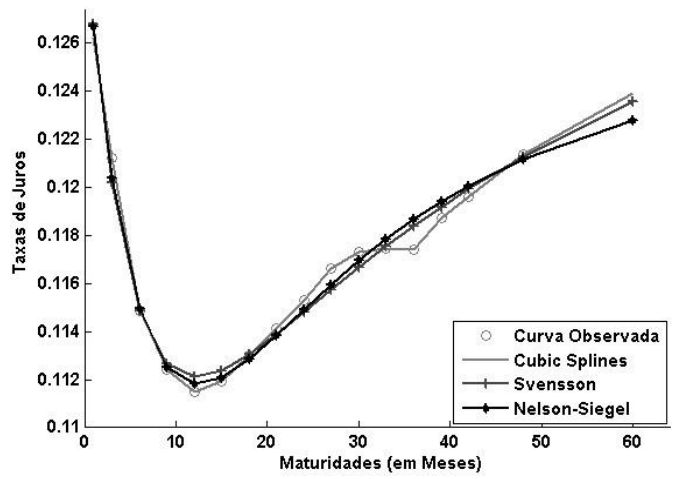

Figura 4 - Curva de juros observada e ajustada - 30/01/2009 Fonte: Elaborada pelo autor.

Nota: Círculos $=$ curva de juros observada, Cinza $=$ curva interpolada por cubic splines, $+=$ ajustada pelo modelo de Svensson $e^{*}=$ ajustada pelo modelo de Nelson-Siegel.

A Figura 5 traz a curva de juros real e ajustada para o dia 26/07/2010, período em que as taxas de juros para as maturidades mais curtas se situavam em patamar inferior aos analisados anteriormente, com inclinação positiva bem definida, refletindo a política monetária de elevação das taxas de juros implementada pela autoridade monetária no período. Nota-se que a curva apresenta claramente inclinação positiva, refletindo expectativa em relação a possível início de ciclo de alta da taxa básica de juros da economia. Pode-se observar que neste caso, em que a curva apresenta inclinação positiva desde as maturidades mais curtas e sem inversões, tanto os modelos paramétricos quanto os não paramétricos exibem boa performance em relação ao ajuste da curva de juros em todas as maturidades. 


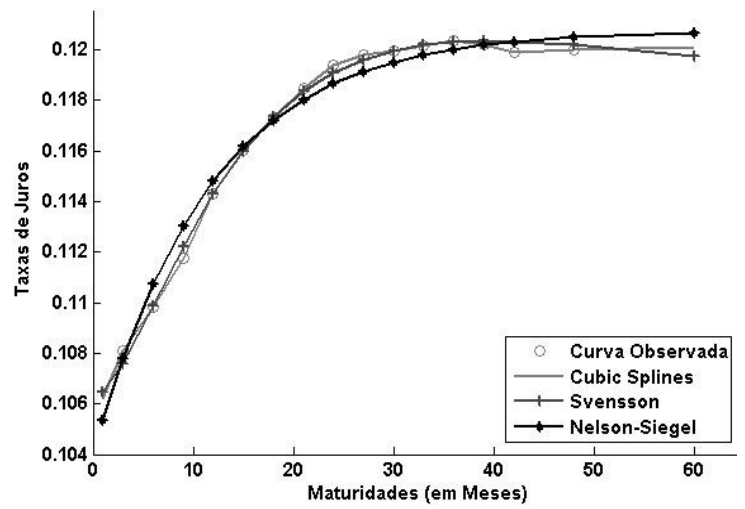

Figura 5 - Curva de juros observada e ajustada - 26/07/2010 Fonte: Elaborada pelo autor.

Nota: Círculos = curva de juros observada, Cinza = curva interpolada por cubic splines, $+=$ ajustada pelo modelo de Svensson e * $=$ ajustada pelo modelo de Nelson-Siegel.

Por último, a Figura 6 traz a curva de juros ajustada e interpolada para mais quatro momentos distintos. $\mathrm{O}$ ajuste dos modelos aos dados reais reforça as observações anteriores de que, na maioria das vezes, os modelos não paramétricos apresentam performance superior para ajuste da curva de juros. Mesmo assim, nos momentos em que a curva não apresenta fortes inversões de curvatura e inclinação, os modelos paramétricos também apresentam ajuste bastante satisfatório.

Apesar dos modelos paramétricos (NELSON; SIEGEL, 1987; SVENSSON, 1994b), apresentarem performance mais pobre que os modelos não paramétricos de cubic splines, (MCCULLOCH, 1971; 1975) e de exponencial splines, eles continuam tendo muito apelo tanto do ponto de vista dos participantes do mercado como de bancos centrais. A atenção dada aos modelos paramétricos se deve principalmente a seu bom desempenho quando o objetivo é fazer previsões da estrutura a termo da curva de juros para fora da amostra. A esse respeito há uma ampla literatura disponível, (DIEBOLD; LI, 2006; DIEBOLD; RUDEBUSCH; ARUOBA, 2006; KOOPMAN; MALLEE; VAN DER WEL, 2010; CALDEIRA; MOURA; PORTUGAL, 2010; ALMEIDA et al., 2008; CAJUEIRO; DIVINO; TABAK, 2009; LAURINI; HOTTA, 2010), sendo os três primeiros referentes a previsões da curva de juros dos EUA, e os demais relativos a curva de juros brasileira. Por sua vez, os modelos não paramétricos não funcionam bem quando se quer ajustar a curva de juros para maturidades muito longas, sendo que as curvas de desconto obtidas a partir desses métodos divergem para as maturidades mais longas, ao invés de convergir para zero. 
Outra vantagem dos modelos paramétricos, além de serem mais parcimoniosos, está na interpretação econômica dos parâmetros, como é o caso do modelo de Nelson e Siegel (1987) reinterpretado por Diebold e Li (2006) em que os três fatores são interpretados como nível, inclinação e curvatura da curva de juros. Essa intuição econômica dos parâmetros possibilita, por exemplo, uma imunização mais eficaz de carteiras de renda fixa, permitindo neutralizar a carteira não só a movimentos paralelos da curva de juros, mas também em relação às mudanças na inclinação e curvatura. A esse respeito, ver Fabozzi (2009).
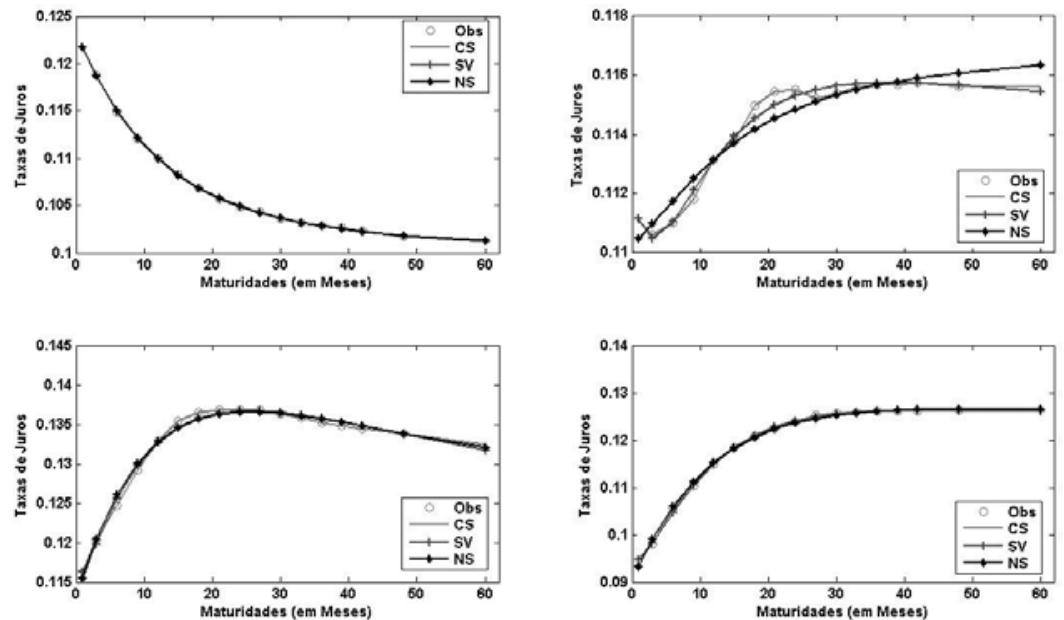

Figura 6 - Curva de juros observada e ajustada - diferentes períodos Fonte: Elaborada pelo autor.

Nota: Círculos $=$ curva de juros observada, Cinza $=$ curva interpolada por cubic splines, $+=$ ajustada pelo modelo de Svensson e * ajustada pelo modelo de Nelson-Siegel.

Na Tabela 2, a seguir, apresentamos estatísticas para o ajuste dos modelos paramétricos. Para critérios de comparação da qualidade do ajuste dos modelos, foram calculados MAE (Mean Absolute Error), MAPE (Mean Absolute Percentage Error) e RMSE (Root Mean Squared Error). Notamos que os dois modelos paramétricos analisados capturam parte substancial da dinâmica da curva de juros, sendo que o modelo de Svensson apresenta melhores critérios de ajuste, principalmente para as maturidades mais curtas. Conforme destacado anteriormente, os modelos não paramétricos ajustam-se perfeitamente nos valores observados da curva de juros, com as desvantagens de serem menos simples na sua estimação e poderem apresentar valores divergentes para maturidades mais longas. 
Tabela 2 - Medidas de Ajuste dos Modelos Paramétricos

\begin{tabular}{lllllll}
\hline & \multicolumn{5}{c}{ Nelson-Siegel } & Svensson \\
Maturidades & MAE & MAPE & RMSE & MAE & MAPE & RMSE \\
\hline M1 & 0.00067 & 0.00630 & 0.00089 & 0.00034 & 0.00323 & 0.00049 \\
M3 & 0.00048 & 0.00455 & 0.00059 & 0.00048 & 0.00458 & 0.00064 \\
M6 & 0.00069 & 0.00633 & 0.00091 & 0.00044 & 0.00413 & 0.00058 \\
M9 & 0.00060 & 0.00540 & 0.00077 & 0.00027 & 0.00243 & 0.00035 \\
M12 & 0.00039 & 0.00354 & 0.00051 & 0.00034 & 0.00311 & 0.00047 \\
M15 & 0.00040 & 0.00339 & 0.00049 & 0.00044 & 0.00377 & 0.00057 \\
M18 & 0.00051 & 0.00424 & 0.00061 & 0.00043 & 0.00364 & 0.00055 \\
M21 & 0.00050 & 0.00418 & 0.00063 & 0.00030 & 0.00245 & 0.00039 \\
M24 & 0.00049 & 0.00402 & 0.00058 & 0.00028 & 0.00232 & 0.00036 \\
M27 & 0.00043 & 0.00345 & 0.00052 & 0.00029 & 0.00240 & 0.00038 \\
M30 & 0.00037 & 0.00299 & 0.00049 & 0.00027 & 0.00216 & 0.00036 \\
M33 & 0.00036 & 0.00294 & 0.00048 & 0.00028 & 0.00222 & 0.00038 \\
M36 & 0.00031 & 0.00249 & 0.00041 & 0.00031 & 0.00246 & 0.00039 \\
M39 & 0.00030 & 0.00231 & 0.00040 & 0.00035 & 0.00274 & 0.00046 \\
M42 & 0.00034 & 0.00264 & 0.00043 & 0.00036 & 0.00283 & 0.00047 \\
M48 & 0.00040 & 0.00315 & 0.00052 & 0.00021 & 0.00164 & 0.00028 \\
M60 & 0.00072 & 0.00571 & 0.00089 & 0.00054 & 0.00417 & 0.00070 \\
\hline F017
\end{tabular}

Fonte: Elaborada pelo autor.

Nota: Todos os modelos foram estimados através do software MATLAB. Os parâmetros de decaimento dos modelos paramétricos foram escolhidos de forma a minimizar o RMSE do ajuste da curva.

\section{Considerações Finais}

Neste artigo são apresentados os principais conceitos relacionados à estrutura a termo da curva de juros e de títulos com e sem cupom, com destaque para os títulos zero-cupom, que são empregados na construção da curva de juros. Também foram apresentadas as inter-relações entre as diversas curvas de juros utilizadas, como curva forward, curva forward instantânea, função de desconto e yield to maturity.

Além disso, foram apresentados os modelos paramétricos e não paramétricos mais usados pelos bancos centrais ao redor do mundo e participantes do mercado em geral na construção e no ajuste de curvas de juros. Os modelos de ajuste da curva de juros são de extrema importância para a precificação de títulos e derivativos, bem como na formulação de políticas monetárias. Os resultados encontrados mostram a superioridade 
dos modelos não paramétricos em relação aos modelos paramétricos no que diz respeito ao ajuste da curva de juros, apresentando bom desempenho em todos os formatos de curvas de juros. Os modelos paramétricos, além de serem mais simples na sua implementação, ajustam bem aos diversos formatos da curva de juros, conforme pode ser observado nos gráficos e na Tabela 2, que traz medidas de ajuste. Sendo que o modelo de Svensson (1994b), com quatro fatores latentes e dois fatores de decaimento, apresenta ajuste superior ao modelo de Nelson e Siegel (1987), principalmente para as maturidades mais curtas. Além disso, os modelos paramétricos, ao permitirem separar a curva de juros em nível, inclinação e curvatura, permitem mais eficiência na montagem de hedge para títulos e carteiras de renda fixa.

Geralmente, o método de estimação depende amplamente do uso que se pretende dar aos dados: não arbitragem nos preços, precificação de títulos de renda fixa e derivativos, extração de informação para análise de investimentos e análise de política monetária. Uma das principais vantagens das técnicas baseadas em splines sobre os modelos paramétricos, como o método de Svensson, é que, ao invés de especificar uma única forma funcional para descrever as taxas à vista, ajusta-se uma curva aos dados, a qual é composta por muitos segmentos, com a restrição de que a curva como um todo seja contínua e suave.

\section{Referências}

ALMEIDA, C. et al.. Does curvature enhance forecasting? International Journal of Theoretical and Applied Finance, v. 12, n. 8, p. 1171-1196, 2009.

. Movimentos da estrutura a termo e critérios de minimização do erro de previsão em um modelo paramétrico exponencial. Revista Brasileira de Economia, v. 62, n. 4, p. 497-510, 2008.

ANG, A.; PIAZZESI, M. A no-arbitrage vector autoregression of term structure dynamics with macroeconomic and latent variables. Journal of Monetary Economics, v. 50, n. 4, p. 745-787, 2003.

BANK FOR INTERNATIONAL SETTLEMENTS - BIS. Zero-coupon yield curves: technical documentation. BIS Papers n. 25. Bank for International Settlements (Department Monetary and Economic ), oct. 2005.

BERNARD, H.; GERLACH, S. Does the term structure predict recessions? Tech. rept., 1996

BLISS, R. R. Testing term structure estimation methods. Advances in Futures and Options Research, v. 9, p. 197-231, 1997.

BOWSHER, C. G.; MEEKS, R. The dynamics of economic functions: modeling and forecasting the yield curve. Journal of the American Statistical Association, v. 103, n. 484, p. 1419-1437, 2008.

BRITO, R. D. O. Essays on the monetary aspects of the term structure of nominal interest rates. PhD. thesis, EPGE - Fundação Getúlio Vargas.

CAJUEIRO, D. O.; DIVINO, J. A.; TABAK, B. M. Forecasting the yield curve for Brazil. Tech. rept., 2009.

CALDEIRA, J. F.; MOURA, G. V.; PORTUGAL, M. S. Efficient yield curve estimation and forecasting in Brazil. Economia, v. 11, n. 1, p. 27-51, 2010. 
COX, J. C; INGERSOLL JR., J. E; ROSS, S. A. A theory of the term structure of interest rates. Econometrica, v. 53, n. 2, 385-407, 1985.

DAI, Q.; SINGLETON, K. J. Expectation puzzles, time-varying risk premia, and affine models of the term structure. Journal of Financial Economics, v. 63, n. 3, p. 415-441, 2002.

DIEBOLD, F. X.; LI, C. Forecasting the term structure of government bond yields. Journal of Econometrics, v. 130, n. 2, p. 337-364, 2006.

DIEBOLD, F. X.; RUDEBUSCH, G. D.; ARUOBA, S. B. The macroeconomy and the yield curve: a dynamic latent factor approach. Journal of Econometrics, v. 131, n. 1-2, p. 309-338, 2006.

DUFFIE, D.; KAN, R. A yield-factor model of interest rates. Mathematical Finance, v. 6 , n. 4, p. 379-406, 1996.

ESTRELLA, A.; HARDOUVELIS, G. The yield curve as a predictor of real economic activity. Journal of Finance, v. 46, n. 2, p. 555-576, 1991.

ESTRELLA, A.; MINSHKIN, F. The preditive power of term structure of interest rate in Europe and the United States: implications for European. Central Bank. European Economic Review, v. 41, n. 7, p. 1375-1401, 1997.

Economic and Finance, v. 2, n. 7, 1996.

FABOZZI, F. J. Bond markets, analysis and strategies. New Jersey: Prentice Hall, 2009.

FAMA, E. F; BLISS, R. R. The information in long-maturity forward rates. American Economic Review, v. 77, n. 4, p. 680-692, 1987.

FILIPOVIC, D. Term-structure models: a graduate course. Springer Finance, 2009, 256 p.

HAGAN, P.; WEST. Interpolation schemes for curve construction. Applied Mathematical Finance, v. 13, n. 2, p. 89-129, 2006.

HARVEY, A. C. R. Forecasting economic growth from bond and stock markets. Financial Analysis Journal, v. 45, n. 5, p. 38-45, sep./oct. 1989.

. The term structure and world economic growth. Journal of The Fixed Income, v. 1, n. 1, p. 7-19, 1991.

HAUBRICH, J.; DROMBOSKY, A. Predicting real growth using the yield curve. Federal Reserve Bank of Cleveland Economic Review, p. 26-35, 1996.

HEATH, D.; JARROW, R.; MORTON, A. Bond pricing and the term structure of interest rates: a new methodology for contingent claims valuation. Econometrica, v. 60, n. 1, p. 77-105, 1992.

HÖRDAHL, P.; TRISTANI, O.; VESTIN, D. A joint econometric model of macroeconomic and term-structure dynamics. Journal of Econometrics, v. 131, n. 1-2, p. 405-444, 2006.

HULL, J.; WHITE, A. Valuating derivative securities using the explicit finite difference method. The Journal of Financial and Quantitaive Analysis, v. 25, n. 1, p. 87-100, 1990.

KOOPMAN, S. J.; MALLEE, M. I. P.; VAN DER WEL, M. Analyzing the term structure of interest rates using the dynamic Nelson-Siegel model with time-varying parameters. Journal of Business and Economic Statistics, v. 28, n. 3, p. 329-451, 2010.

LAURINI, M. P.; HOTTA, L. K. Bayesian extensions to diebold-li term structure model. International Review of Financial Analysis, v. 19, n. 5, p. 342-350, 2010.

LAURINI, M. P.; MOURA, M. Constrained smoothing BB-splines for the term structure of interest rates. Insurance: Mathematics and Economics, v. 46, n. 2, p. 339-350, 2010. 
LITTERMAN, R.; SCHEINKMAN, J. Common Factors Affecting Bond Returns. The Journal of Fixed Income, v. 1, n. 1, p. 54-61, 1991.

MCCULLOCH, J. H. Measuring the term structure of interest rates. Journal of Business, v. 44, n. 1, p. 19-31, 1971.

. The tax-adjusted yield curve. Journal of Finance, v. 30, n 3, p. 811-830, 1975.

MINSHKIN, F. S. What does the term structure tell us about future inflation? Journal of Monetary Economics, v. 25, n. 1, p. 77-95, 1990.

NELSON, C. R.; SIEGEL, A. F. Parsimonious modeling of yield curves. The Journal of Business, v. 60, n. 4, p. 473-489, 1987.

ROSSI, J. W. A estrutura a termo da taxa de juros: uma síntese. Pesquisa e Planejamento Econômico, v. 26, n. 3, p. 521-548, 1996.

SHEA, G. S. Pitfalls in smoothing interest rate term structure data: equilibrium models and spline approximations. The Journal of Financial and Quantitative Analysis, v. 19, n. 3, p. 253-269, 1984.

SHILLER, R. J.; MCCULLOCH, J. H. The term structure of interest rates. NBER Working Paper Series n. 2341. National Bureau of Economic Research, 1987.

STOCK, J. H.; WATSON, M. New indexes of coincident and leading indicators. Tech. rept., 1989. SVENSSON, L. E. O. Estimating and interpreting forward interest rates: Sweden 19921994. IMF Working Papers n. 94/1 14. International Monetary Fund, 1994a.

. Estimating and interpreting forward interest rates: Sweden 1992-1994. IMF

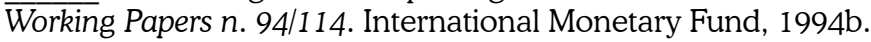

TABAK, B. M.; TABATA, A. Surpresas na política monetária e a estrutura a termo de taxa de juros brasileira. Revista de Economia Aplicada, v. 8, n. 3, p. 383-399, 2004.

VASICEK, O. An equilibrium characterization of the term structure. Journal of Financial Economics, v. 5, n. 2, p. 177-188, 1977.

YU, W.; ZIVOT, E. W. Forecasting the term structure of treasury and corporate yields: dynamic Nelson-Siegel models evaluation. SSRN Working Paper. SSRN.

Recebido em: 10/05/2010.

Aceito em: 20/08/2010. 